\title{
Total diz protezi sonrası diz çevresi periprostetik kırıkları
}

\section{Periprosthetic fractures around the knee following total knee replacement}

\author{
Mehmet Atıf Erol Aksekili, Mahmut Uğurlu
}

Yıldırım Beyazıt Üniversitesi Tıp Fakültesi, Ortopedi Anabilim Dalı, Ankara

Total diz protezi sonrası periprostetik kırık görülme ihtimali düşük olmasına rağmen, bu uygulamaların her geçen yıl artması, ameliyattan sonra aktivitenin artışı ve beklenen yaşam süresinin uzamasıyla birlikte, periprostetik kırıklarla daha fazla karşılaşmaktayız. Bu kırıklar, femur, tibia ve patellar bölgeyi kapsar. Suprakondiller femur kırıkları diğerlerine oranla daha sık görülür. Bu tip karmaşık kırıkların tedavisi için, cerrahın hem travma rekonstrüktif teknik hem de artroplasti konusunda tecrübesi olması gerekmektedir. Tedavideki amaç, kırığın altı aydan önce kaynaması, kırık öncesi diz hareketlerinin sağlanması ve ağrısız diz elde etmektir. Konservatif tedavi, plaklama, intramedüller çivi, revizyon artroplasti gibi tedavi alternatifleri bulunmaktadır. Öte yandan, literatürde çok kesin bilgiler olmadığı için, tedavi yaklaşımıyla ilgili tek akış şeması bulunmamaktadır. Kilitli plakların gelişmesiyle birlikte, hastaların büyük bir kısmına cerrahi tedavi uygulanmaya başlanmıştır. Bu çalışmada, total diz protezi sonrası diz çevresi periprostetik kırıkların nedeni, risk faktörleri, sıklığı, sınıflandırması ve güncel tedavi seçenekleri konusunda güncel bilgiler derlenmiştir.

Anahtar sözcükler: diz protezi, total; protez çevresi kırıklar; kilitli plak; intramedüller çivileme; cerrahi düzeltme
Even though the likelihood of periprosthetic fracture around a total knee arthroplasty is low, we are experiencing periprosthetic fractures more often due to increasing number of these operations each year, due to increasing postoperative activity level and life expectancy. These fractures include femoral, tibial and patellar zone. Supracondylar femoral fractures are seen more often compared to the latter. To treat this type of complex fractures, surgeons need to be experienced on both traumatic reconstuction techniques and arthroplasty. The aim of treatment is union of fracture before 6 months, maintenance of pre-fracture knee movements, and to obtaining a pain-free knee joint. The alternatives are: conservative treatment, plating, intramedullary nailing, and revision of arthroplasty. On the other hand, no single current algorithm is present for treatment approach due to lack of precise data in literature. With the improvement of locked plates, surgical treatment has started to be performed on most of the patients. In this study, we reviewed the causes, risk factors, incidence, classification, and current treatment options of periprosthetic fractures around total knee arthroplasty.

Key words: knee arthroplasty, total; periprosthetic fractures; locked plate; intramedullary nailing; surgical revision ayat kalitesinin ve beklenen yaşam süresinin artmasıyla birlikte, total diz protezi (TDP) uygulama insidansı da her geçen yıl artmaktadır. TDP uygulamasına bağlı olarak, periprostetik kırık (PPK) görülme sıklığı da artar. TDP sonrası PPK olasılığı \%0,3-2,5'tir. ${ }^{[1-4]}$

Yaşlı hasta grubunda TDP sonrası aktivitenin artışı, bu problemin görülme olasılığını da arttırır. ${ }^{[5-8]}$ PPK tedavisini, protezin stabilitesi ve kırığın tipi şekillendirir. Tedavinin kompleks olmasının en önemli nedenlerinden birisi, osteopeni ile birlikte kemik stoğunun az olmasıdır. Kırık, ameliyat içi veya ameliyat sonrası görülebilir. Ameliyat sonrası erken dönemde görülen kırıklar, genellikle stres dağılımının değişmesi, kortikal delinme, aşırı patella rezeksiyon gibi teknik problemlerden kaynaklanır. Geç dönemde ise, genellikle düşük enerjili travmadan kaynaklanır.

Tedavideki amaç, $0-90^{\circ}$ hareket açıklığıyla birlikte, ağrısız bir diz elde etmek ve altı ay içinde kaynamayı sağlamaktır. ${ }^{[9]}$ Kabul edilebilir dizilim; $5 \mathrm{~mm}$ 'den az translasyon, $5-10^{\circ}$ 'den az açlanma, $10^{\circ}$ 'den az rotasyon ve $1 \mathrm{~cm}$ 'den daha az kısalıktır. ${ }^{[10]}$ PPK tedavisi oldukca komplekstir ve \%41 oranında komplikasyon görülür; revizyon oranı ise \%29'dur. ${ }^{[11,12]}$

- Illetişim adresi: Yrd. Doç. Dr. Mehmet Atıf Erol Aksekili, Yıldırım Beyazıt Üniversitesi Tıp Fakültesi, Ortopedi Anabilim Dalı, 06800, Ankara Tel: 0507 - 2396056 e-posta: atifaksekili@yahoo.com

- Geliștarihi: 8 Nisan $2015 \quad$ Kabul tarihi: 8 Nisan 2015 


\section{SUPRAKONDILER FEMUR KIRIKLARI}

\section{Nedeni ve Risk Faktörleri}

TDP sonrası görülen suprakondiler femur kırıkları, eklemin $15 \mathrm{~cm}$ proksimali ya da implantın $5 \mathrm{~cm}$ proksimalini içeren bölgede görülen kırıkları kapsar. ${ }^{[13,14]}$ Femoral suprakondiler kırıkların ameliyattan 2-4 yıl sonra görülme oranı \%0,3-2,5'tir. ${ }^{[13,15,16]}$ Genellikle, iyi tespit edilmiş femoral komponentte, düşük enerjili travma sonrası görülür. Trafik kazaları, TDP sonrası sıkı dizde yapılan manipülasyon ve epileptik nöbet, diğer sık görülen oluş nedenlerindendir ${ }^{[17]}$. Bu kırıklar, genellikle aksiyel ve torsiyonel kurvetlerin kombinasyonu sonucu oluşur. En önemli risk faktörü osteopenidir. ${ }^{[18,19]}$ Romatoid artrit, kronik steroid kullanımı ve ileri yaş ise, osteopeninin risk faktörlerindendir. ${ }^{[20]}$ Navigasyon yardımlı TDP uygulanmasında kullanılan pin delikleri de risk faktörleri arasında sayılmaktadır. ${ }^{[21]}$ Diğer risk faktörleri arasında; osteolizis, kadın cinsiyet, nörolojik problemler, revizyon TDP, rotasyonu kısıtlayıcı protezler bulunur; ${ }^{[22,23]}$ anterior femoral çentiklenme konusunda ise farklı görüşler bulunmaktadır. Ritter ve arkadaşlarının çalışmasına göre, çentiklenme olan ve olmayan olgular arasında fark bulunamamıştır. ${ }^{[1]}$ Biyomekanik çalışmalarda ise, 3 mm'den fazla, keskin kenarlı ve protezin bitim bölgesine gelen çentiklenmede, yüksek stres yoğunluğu oluştuğu gösterilmiştir. ${ }^{[24,25]}$ Bütün bunlara ek olarak, Culp ve arkadaşlarının çalışmasına göre, anterior femoral çentiklenme, suprakondiller femur kırığı riskini arttırmaktadır. ${ }^{[23]}$

\section{Sınıflandırma}

Birçok sınıflandırma sistemi olmasına rağmen, tek başına genel kabul olmuş sınıflandırma yoktur. Sınıflandırmada, yer değiştirme, kemik stoğu, kırığın implanta olan uzaklığı ve implantın stabilitesi gibi faktörler rol oynar. Litaratürde en sık kullanılan, Lewis ve Rorabeck sınıflandırma sistemidir (Tablo 1). ${ }^{[26]} \mathrm{Bu}$, femoral komponentin tespit durumu ve kırığın yer değiştirmesini baz alan bir sınıflandırmadır. Ancak, bu sınıflandırmada implanttan kırığa olan uzaklık göz önünde bulundurulmaz. Bu durum, özellikle redrograd kanal içi çivi ya da kilitli plak seçenekleri değerlendirildiğinde önemli olmaktadır. Backstein ve Su'nun yaptığı sınıflandırma, bu konuda daha yardımcıdır (Tablo 2 ve 3 ). ${ }^{[27]}$

\section{Tedavi}

Konservatif tedavi; iskelet traksiyonu, splintleme, alçı ve breysleme gibi yöntemleri kapsar. Günümüzde iskelet traksiyonu, enfeksiyon, sinir felci, uzun yatak istirahati gerektirmesi gibi komplikasyonlarından dolayı tercih edilmemektedir. Konservatif tedavi, genel durumu cerrahiye izin vermeyen, interkondiller alana uzanmayan ayrışmamış kırığı olan ve implantın stabil olduğu hastalara uygulanabilir. Bu kırıklar, genellikle sınıflandırma sistemlerinde Tip 1 olan gruptur. Alçı ile 4-6 hafta hareketsiz bırakılıp, yük verdirilmeden tedavi edilebilir. Eğer hastanın takiplerinde redüksiyon kaybı oluyorsa, cerrahi tedaviye geçmek gerekebilir. ${ }^{[28]}$ Ancak, Tip 1 kırıkta epikondiller bölgede avulsiyon kırığı da varsa, cerrahi tedavi önerilmektedir. ${ }^{[29]}$ Chen ve arkadaşları, yaptıkları derlemede, TDP sonrası femoral bölgede görülen PPK'nin konservatif ve cerrahi sonuçlarını karşılaştırmışlardır. ${ }^{[15]}$ Ayrışmamış kırıklardaki başarı oranını \%83 olarak belirtmişlerdir. Kırık hattının ayrışmış olduğu hasta grubunda, konservatif ve cerrahi grup açısından hasta memnuniyet oranları $\% 67$ ve $\% 61$ 'dir. Bununla beraber, komplikasyon oranını cerrahi grupta daha fazla olarak belirtmişlerdir.

Ayrışmış kırıklarda, redüksiyonu konservatif yöntemle sağlamak ve sürdürmek zordur; yanlış kaynama, kaynamama gibi problemler yüksek oranda görülebilmektedir. ${ }^{[28]}$ Redükte edilemeyen ayrışmış kırıklarda, cerrahi tedavi gerekir.

Konvansiyonel plaklama yöntemi ile, ciddi oranda yanlış kaynama ve mekanik yetmezlik bildirilmiştir. ${ }^{[30,31]}$

Tablo 1. Suprakondiler femoral kırıklar için Levis ve Rorabeck sınıflandırması

\begin{tabular}{ll}
\hline Tip 1 & Ayrışmamış, protezde gevşeme yok \\
Tip 2 & Ayrışmış, protezde gevşeme yok \\
Tip 3 & Ayrışmış veya ayrışmamış, protez gevşek
\end{tabular}

Tablo 2. Backstein ve arkadaşlarının suprakondiller femur kırıkları için sınıflandırması

Tip F1 Kırık hattının distalinde retrograd çivileme için yeterli kemik stoğu mevcut.

Tip F2 Kırık hattının distalinde retrograd çivileme için yeterli kemik stoğu yok.

Ek kriterler S (stabil protez) L L (gevşek protez) g (yeterli kemik stoğu) P (zayıf kemik stoğu)

Tablo 3. Su ve arkadaşlarının suprakondiller periprostetik kırıkları için yaptığı çalışma

Tip 1 Kırık hattı femoral komponentin proksimalindedir.

Tip 2 Kırık hattı femoral komponentin proksimalinden köken alır ve proksimale uzanır.

Tip 3 Kırık hattının herhangi bir parçası femoral komponentin ön üst kenarının distaline uzanım gösterir. 
Bunun muhtemel nedeni, cerrahi yaklaşımdan ötürü vasküler yetmezlik ve osteoporotik kemiği yeterince tespit edememektir. ${ }^{[32]}$ Modern tedavi yöntemlerinin gelişmesiyle birlikte, minimal disseksiyonla daha stabil tespit sağlanabilmektedir. Günümüzde, Rorabeck ve Lewis Tip 1 ve 2 PPK'de, redrograd kanal içi çivi ve kilitli plaklar en sık kullanılan tespit araçlarıdır. Herrara'nın yaptığı derlemeye göre, bu teknikler konservatif tedavi ve konvansiyonel plaklama ile karşılaştırıldığında, çok daha düşük oranda kaynamama riski bulunmaktadır. ${ }^{[33]}$

Minimal invaziv yöntemin kullanıldığı kilitli plakların ve farklı açılarda vida konulmasına izin veren poliaksiyel sistemlerin gelişimiyle, diz protezi sonrası oluşan PPK'nin tedavisinde daha iyi sonuçlar elde edilmeye başlanmıştır. Minimal invaziv yöntemde, kemiği çevreleyen yumuşak doku ve periosteum korunarak, kırık iyileşme biyolojisine daha uygun bir kaynama ortamı sağlanmaktadır. Kilitli vidalar sayesinde, plak kemiğe tam temas etmeden, internal fiksatör gibi uygulanırsa, altındaki bölgede daha az rezorbsiyona yol açar ve periferal vaskülarizasyonun korunmasına daha çok izin verir. Bu yöntem uygulanan iki çalışmada, \%86-90 oranında kaynama elde edilmiş ve hastaların önemli bir kısmı ameliyat öncesi fiziksel aktivitelerine kavuşmuştur. ${ }^{[34]}$

Suprakondiller PPK'de kilitli plakların kullanımının artması ve gelişmesiyle birlikte, teknikte bazı varyasyonların kullanım ihtiyacı ortaya çıkmıştır. Bazı kilitli vidalar, proteze temas etmemesi ve tek kortikal tutunum sağlaması için modifiye edilmiştir. Poliaksiyel vidalar ise, plağa kilitlenmeden önce protezin çevresinden geçerek çift kortikal tespit sağlaması amacıyla geliştirilmiştir. ${ }^{[34]}$ Çift kortikal tespit, sistemin direncini arttırırıp esnekliğini azalttığı için, ikincil kemik iyileşmesini olumsuz etkiler. Son zamanlarda geliştirilen uzak lateral kortikal kilitleme sistemi, proksimal vida deliğinin plağın kemik üzerinde kaymasına izin vermesiyle, sistemin direncini düşürmeden esnekliğin artmasını hedefler. ${ }^{[35]}$ Böylece, ikincil kemik iyileşmesini arttırarak, yüksek hacimli simetrik kallus oluşumunu uyarmaktadır. ${ }^{[36]}$

Birçok yazar, tıpkı suprakondiller femur kırığında olduğu gibi, suprakondiller PPK'de direkt lateral yaklaşımı tanımlamışlardır. ${ }^{[37]}$ Bu yaklaşım, minimal invaziv yöntemin kullanılmasına izin verir. ${ }^{[38]}$ Anterior yaklaşım kullanıldığında ise, kırık hattı daha iyi görülüp direkt redüksiyon yapılabilmektedir. Ayrıca bu yaklaşım, protezin stabilitesinden şüphelenildiği durumlarda direkt değerlendirme imkanı verir. ${ }^{[38]}$ Revizyon protez ihtiyacı olursa, aynı yaklaşımla ameliyata devam edilebilmektedir. Eski kesinin kullanılması sayesinde paralel kesiden kaçınılması da bir diğer avantajıdır. Bütün bu avantajlarının yanı sıra, geniş yumuşak doku disseksiyonu, kaynamama riskini arttırmaktadır.

Kilitli plaklar birçok avantaj sağlasa da, implant yetmezliği halen önemli bir konudur. Osteoporotik kemiğe proksimal tek kortikal vidaların uygulanması, implant yetmezliğini arttıran bir nedendir. ${ }^{[38]}$ İmplant yetmezliğine yol açabilecek diğer nedenler olan, düşük kemik kalitesi, düşük kemik stoğu, protezle birlikte kırıktan kaynaklı kan akımının değişimi gibi durumlar, hastaların büyük çoğunluğunda bulunmaktadır. Tespiti desteklemek amacıyla, serklaj gibi materyaller kullanılabilir. Ebraheim ve arkadaşlarının yaptığı çalışmaya göre, minimal doku disseksiyonu ile kilitli plağın çevresine serklaj uygulanması, komplikasyon oranını düşürmekte, kaynama süresini kısaltmakta ve revizyon oranını azaltmaktadır. ${ }^{[39]}$

Eğer kırık kapalı redükte edilebiliyorsa, minimal yumuşak doku travması ve biyomekanik avantajlarından dolayı, retrograd intramedüller çivi çok iyi bir alternatiftir. Literatürde, bu yöntemle tedavi edilen hastalarda en yüksek kaynama oranları bildirilmiştir. Bu tekniğin başarılı olmasının nedenleri arasında; minimal yumuşak doku travması oluşturması, biyomekanik olarak yeterli stabilite sağlaması, kanal içi oyma işlemi nedeniyle iyileşmeyi uyarması sayılabilir. ${ }^{[40]}$ Chen ve arkadaşlarının yaptığı biyomekanik çalışmaya göre, femurçivi teması ve distal kilit vidalarının kullanımı, rotasyonel stabiliteyi önemli ölçüde arttırmaktadır. ${ }^{[41]}$ Çivinin giriş yerinin direkt görülmesi için, artroskopi yardımlı yöntemler ve osteopeni olduğunda distal vidaları desteklemek amacıyla, sementin uygulandığı retrograd çivileme gibi yöntemler de tanımlanmıştır. ${ }^{[40]}$ illeri osteoporoz olgularında, distal vida kemik tutunumunu arttırmak amacıyla, sementli çivi uygulaması tanımlanmıştır. ${ }^{[42]}$ Çivi ile kortikal bölge arasına sement uygulanınca stemli revizyon protezi gibi hareket etmektedir. Yine, distal tespiti kuvvetlendirmek için bolt ve vidalar önerilmektedir. ${ }^{[42]}$

Retrograd kanal içi çivi, kırığın distal parçası distal kilitleme vidaları ile yeterince tespit edileceği zaman uygulanabilir. ${ }^{[43]}$ Arka çapraz bağı koruyan birçok protez tasarımında, interkondiller çentik $11-21 \mathrm{~mm}$ çapındadır ve retrograd çivileme için uygundur. Protez tasarımı,her ameliyattan önce değerlendirilmelidir. Femoral komponentin uygun tasarlanmamış olduğu durumlarda, elmas uçlu burr kullanılarak, çivi girişi için uygun hale getirilebilir. ${ }^{[4]}$ Yalnız, bu yöntemle oluşan metal debris kontaminasyonu minimalize edilmeye çalışılsa da, protezin sağkalımı açısından, bu yöntemden mümkünse kaçınılmalıdır. Patella paja, eklem ankilozu, çok parçalı kırık hattı, distal kilitleme vidalarının tespit edeceği kadar kemik stoğunun olmaması, retrograd çivilemenin kontrendikasyonlarındandır. ${ }^{[45]}$ 


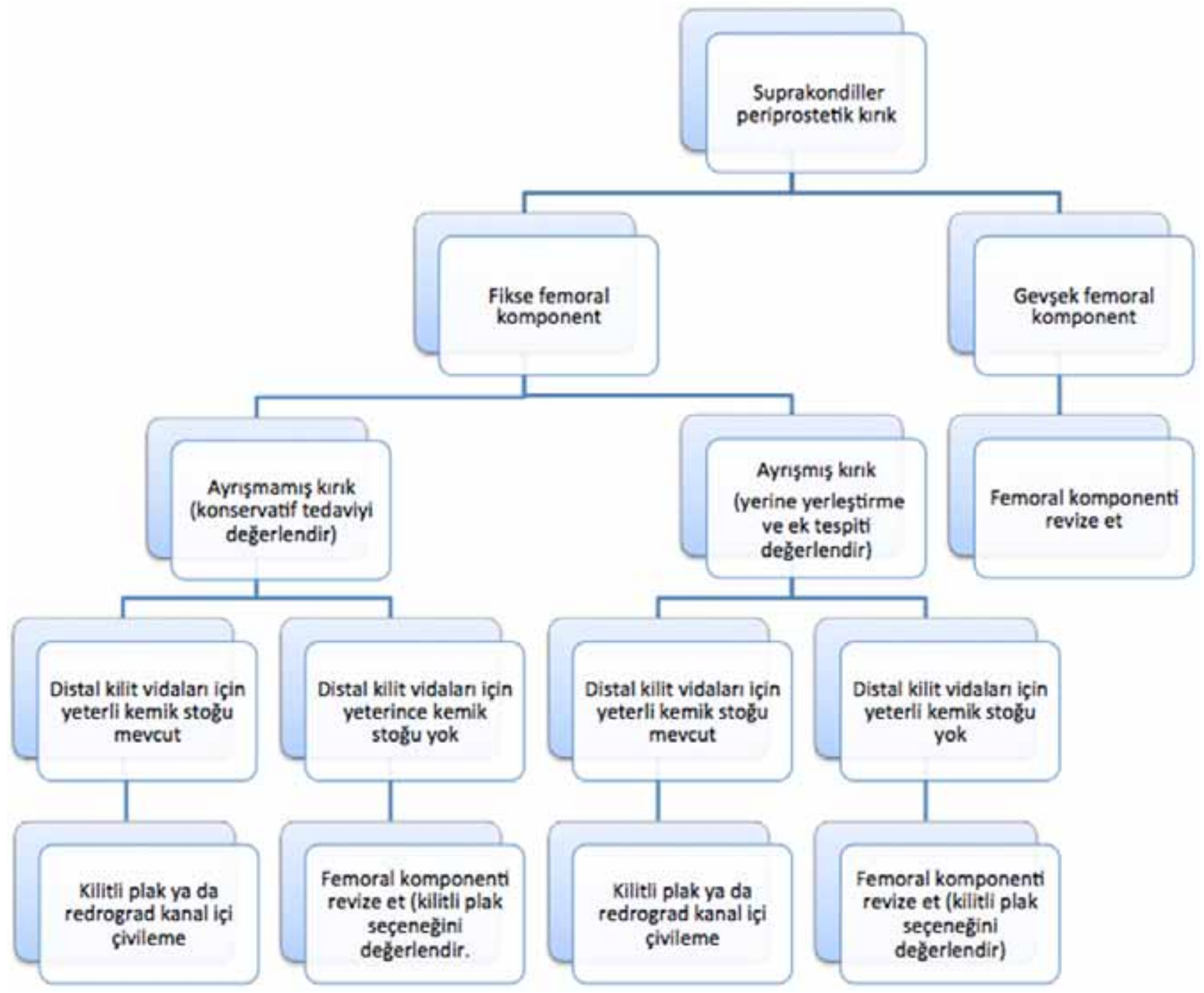

Şekil 1. Distal femur periprostetik kırıklarında tedavi akış şeması.

Retrograd çivi için, femoral protezin orijinal dizilimi de önemlidir. Protez fleksiyonda ya da lateralize ise, femoral kanalın giriş noktası eksentrik olabilir. Eksentrik giriş noktası, çivinin girişini engelleyebilir veya yanlış yerden girmesine yol açarak redüksiyonu bozabilir. ${ }^{[38]}$

Son zamanlarda yapılan sistematik bir çalışmaya göre, retrograd çivi ile kilitli plak karşılaştırıldığında, kaynamama ve revizyon oranları açısından fark bulunamamıştır. ${ }^{[46]}$ Fakat bu çalışmaya göre, çivilemede daha yüksek yanlış kaynama bildirilmiştir. Bu bahsedilen çalışma, Seviye 4 bir çalışmadır ve daha kesin karar vermek için, çalışma düzeyi daha yüksek çalışmalara ihtiyaç vardır.

PPK ile birlikte komponentte gevşeme bulunuyorsa veya komponentlerin dizilimi uygun değilse, diz stabilitesi ve fonksiyonunu tekrar kazanmak için, femoral komponenti revize etmek gerekir (Şekil 1).[26] Ayrıca, kırı̆ı̆ distalinde intramedüller çivi veya plakla tespit edecek kadar kemik dokusunun olmaması durumunda da, revizyon seçeneğini değerlendirmek gerekir. PPK sonrası tespit ardından kaynamama gelişmesi durumunda da protezin revizyonuna ihtiyaç duyulabilir (Şekil 2). Revizyon seçeneği olarak; menteşeli diz protezi, tümör rezeksiyon protezi veya hastaya spesifik protez gerekebilir. Yapılan bazı çalışmalara göre; revizyon seçeneği uygulanıldığında hastaların klinik skorlarında erken dönemde düzelme görülmesine rağmen, enfeksiyon, tekrar kırık oluşması, hematom, pulmoner emboli gibi komplikasyonlar yüksektir. ${ }^{[38]}$ Hastanın komorbiditesi, uzun ameliyat süresi ve geniş yumuşak doku disseksiyonu, komplikasyonları arttıran nedenlerdendir. Kısıtlamalı revizyon protezlerin en önemli komplikasyonlarından biri ise aseptik gevşemedir. ${ }^{[47]}$ 

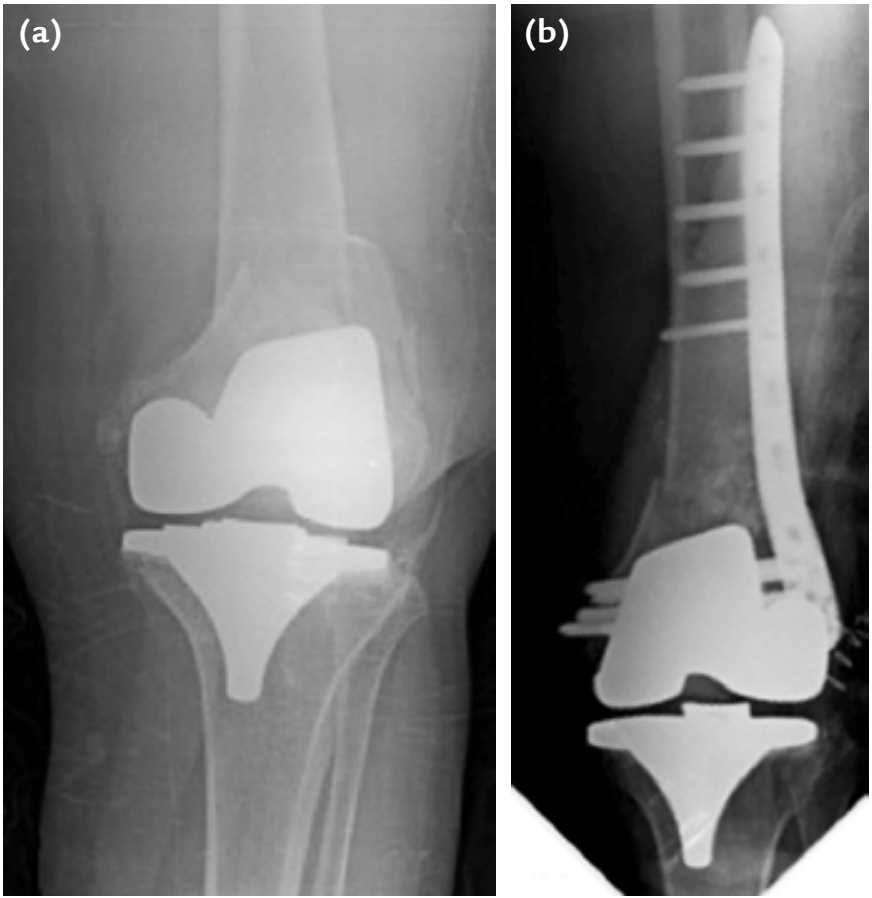

Sekil 2. a-d. Suprakondiller femoral periprostetik kırık sonrası üzerine (c) revizyon uygulanan hastanın görüntüleri (d).
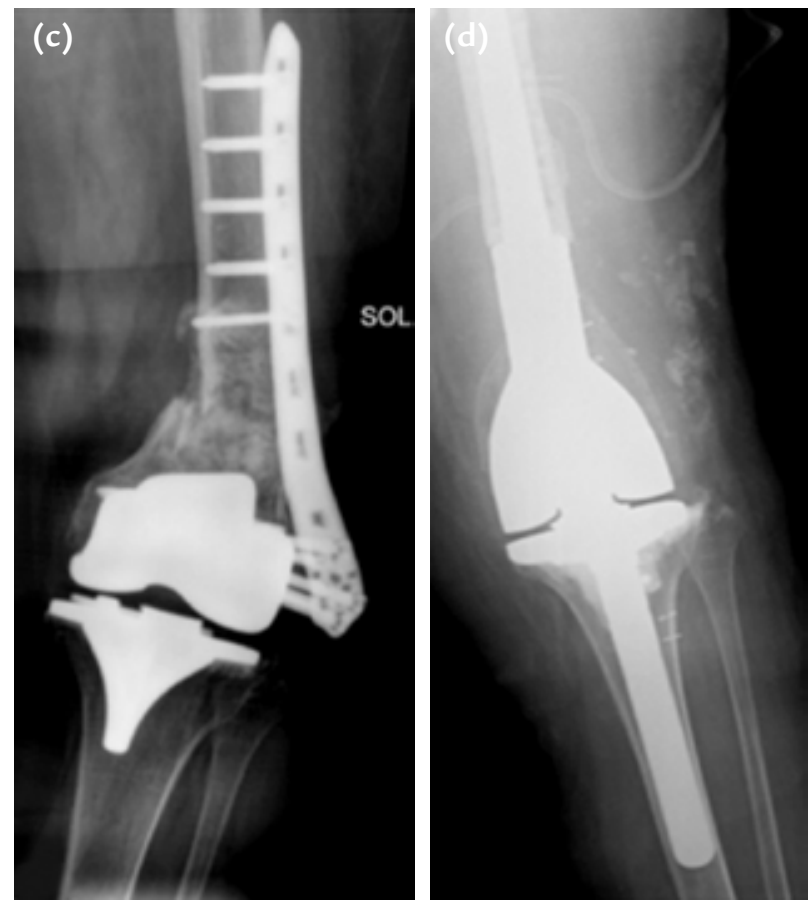

(a) kilitli plak uygulanan hastada (b) kaynamama gelişmesi

\section{TIBIANIN PERIPROSTETIK KIRIKLARI}

\section{Nedeni ve Risk Faktörleri}

Diz protezi sonrası tibianın periprostetik tibia kırıkları nadir görülen komplikasyondur. Ameliyat içi görülme oranı $\% 0,1$ civarında iken, ameliyat sonrası görülme oranı yaklaşık \%0,4'tür. ${ }^{[7]}$ Revizyon artroplastide bu oran artmaktadır (ameliyat içi \%0,36 ve ameliyat sonrası \%0,48). ${ }^{[48]}$ Ameliyat sonrası kırıkların en önemli nedeni travmadır, fakat travma olmadan stres kırığı da görülebilir. Tibial kırıkların en önemli nedenleri; komponent gevşemesi, instabilitesi, dizilim bozukluğu ve eklem instabilitesidir. Lotke ve arkadaşları, varus pozisyonunda implante edilen tibial komponentin mediyal plato kırıklarıyla ilişkisini ortaya koymuştur. ${ }^{[49]}$

\section{Sınıflandırma}

Literatürde en sık kullanılan sınıflandırma, Felix ve arkadaşlarının, kırığın anatomisi, protezin stabilitesi ve kırığın oluş zamanını baz alarak yaptığı çalışmadır. ${ }^{[7]} \mathrm{Bu}$ sınflandırmaya göre, kırık dört tipe ve her tip de kendi içinde üç alt tipe ayrılır (Şekil 3). Tip 1, tibial platoyu; Tip 2, tibial platonun inferiorunda steme komşu bölgeyi; Tip 3, tibial stemin distalini; Tip 4 ise tibial tüberkülün de dahil olduğu kırıkları kapsar. Radyografide protezin sağlam olduğu kırıklar Tip A, gevşek olanlar Tip B ve ameliyat içi kırıklar ise Tip C olarak adlandırılır.

\section{Tedavi}

Tip1 kırıklarda, genellikle protezde gevşeme mevcuttur. Yeterli destek sağlamak için kemik yüzeylerin restorasyonu gerekir. Tip 1A kırıklar, alçı ile tespit edilip yük verdirilmeden tedavi edilebilir. Tip 1B kırıkların tedavisi için revizyon artroplasti gerekir. Gevşek protezle birlikte düşük kemik kalitesinin olduğu PPK'ların tedavisi oldukça karmaşıktır. Kırık parçayla birlikte gevşek protez çıkarıldığında, büyük bir kemik kaybı oluşur.

Tip 1C kırıklar, protez implante edilmeden önce, açık yerine yerleştirme iç tespit ile tedavi edilebilir. ${ }^{[37]}$ Tip 2 kırıklarda, Tip 1'lerden farklı olarak, protez stabil veya instabil olabilir. ${ }^{[29]}$ Tip $2 \mathrm{~A}$ ayrışmamış kırıklar, eğer ekstremitenin dizilimi iyi ise, hareketsiz bırakma ile ve yük verdirilmeden konservatif tedavi edilebilir. Tip 2B kırıklarda ise, dizilim nasıl olursa olsun, kanal içi uzun stem kullanılarak revizyon gerekmektedir. ${ }^{[29]}$ Eğer Tip 2 kırık ameliyat sırasında tespit ediliyorsa (Tip 2C), ek tespit gerektirebilir. Kırık ayrışmamış ise, ameliyattan sonra ekstremite hareketsiz bırakılarak tedavi edilebilir.

Tip 3A kırıklar protez dışı olduğu için protez stabildir. Tip 3A kırıklar, temel kırık tedavi prensiplerine göre tedavi edilebilir. Tip 3B kırıklar da uzun stemli protezlerle tedavi edilebilir. Fakat kırık distalde ise, revizyon kaynama elde edildikten sonra yapılabilir. Tip 3C kırıklar konservatif tedavi edilebilir. ${ }^{[48]}$ 


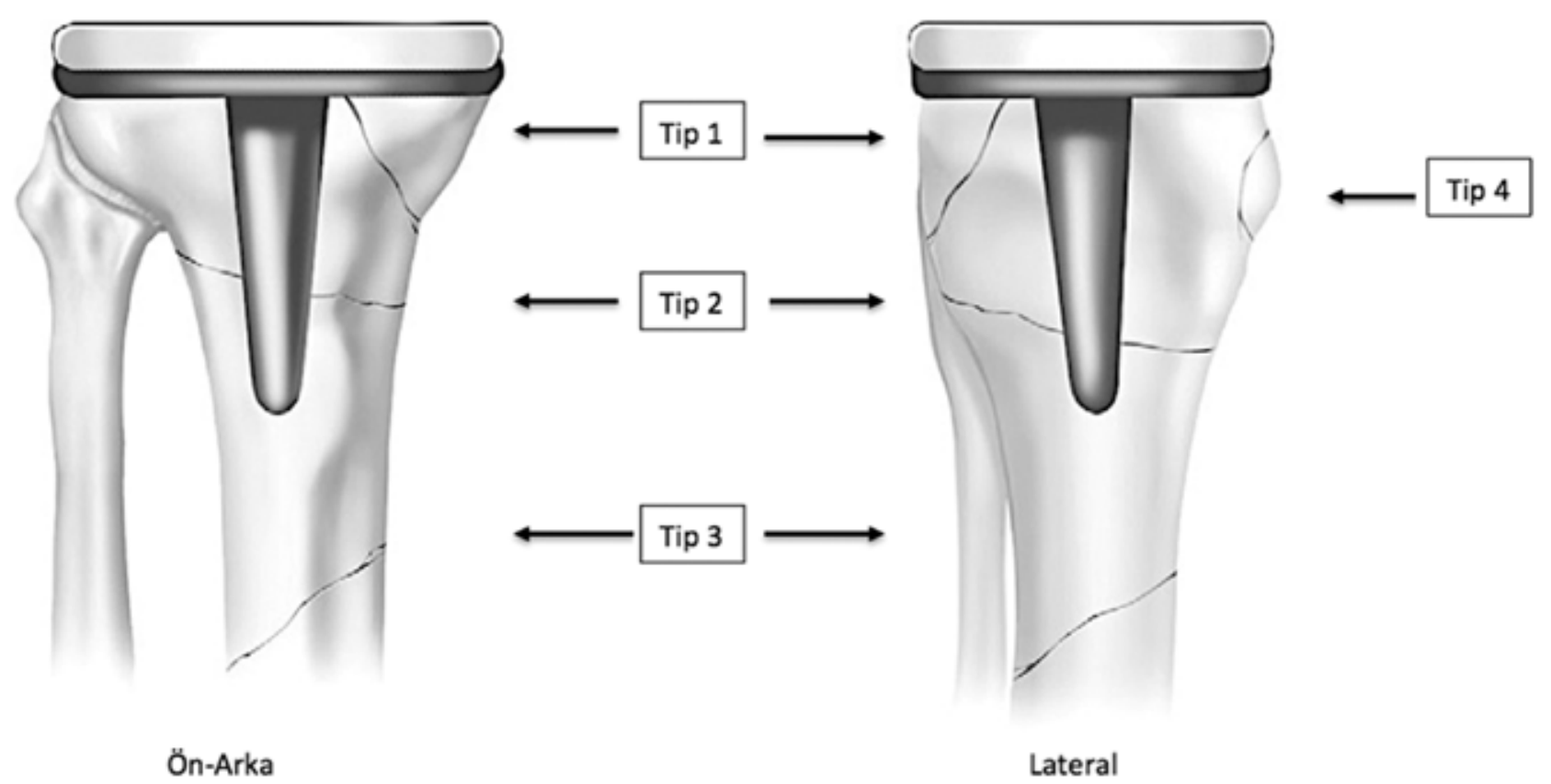

Şekil 3. Felix ve arkadaşlarına göre tibia periprostetik kırıklarının sınıflandırması.

Tip 4 kırıklarda tedavi, ekstansör mekanizmanın bütünlüğü değerlendirilerek planlanmalıdır. Tip 4A kırıklarda, fonksiyonel olarak sağlam ekstansör mekanizma olduğu için, konservatif tedavi seçilebilir. Hanssen ve arkadaşları, Tip 4 kırıklarda tibial kemik parçanın tespitinin semitendinozus grefti veya poliprolen meşle yapılmasını önermişlerdir. ${ }^{[50]}$ Eğer tibial komponentte gevşeme varsa, revizyon artroplasti düşünülmelidir. Revizyon ameliyatında, tibial stem normalden uzun kullanılmalıdır. Böylece, kırık ile tibial cisim tespit edilmiş olur. Tibial komponentin tespitinden sonra, instabil kemik kırıkları için ek iç tespit gerekebilir. Proksimal tibiadaki kemik kaybı için, implantın stabilitesi açııından, metal destekler konulabilir. ${ }^{[51]}$ Eğer kemik kaybı $5 \mathrm{~cm}$ 'den fazla ise, strut allogreft veya megaprotez kullanılabilir. ${ }^{[50]}$

\section{PATELLA PERIPROSTETIK KIRIKLARI}

\section{Nedeni ve Risk Faktörleri}

Diz protez sonrası görülen PPK, suprakondiller femur kırıklarından sonra ikinci en sıklıkta görülür. Patellar yüzey yenilemesi yapıldıktan sonra \%0,2-21 oranında, yüzey yenileme yapılmadan önce $\% 0,05$ oranında görülmektedir. ${ }^{[52]}$ Patellar kırık görülme sıklığı, birincil diz protezlerinden sonra $\% 1,19$, revizyon diz protezinden sonra ise $\% 0,15-12$ oranında bildirilmiştir. ${ }^{[53]}$ Femoral ve tibial PPK'nin aksine, erkeklerde görülme oranı daha yüksektir ${ }^{[54]}$. Bu durumun asıl nedeni tam olarak bilinmese de, erkeklerde aktivitenin ve vücut ağırlığının fazla oluşundan kaynaklandığı düşünülmektedir.[54] Patellar PPK, direkt travma veya yetmezlik kırığı şeklinde görülebilir. ${ }^{[52]}$ Tanımlanmış risk faktörlerinin arasında; romatoid artrit, uzun süreli steroid kullanımı, patellar nekroz, alt ekstremitenin ya da protezin dizilim bozukluğu, PCL kesen protez tasarımı, belirli tip patellar protezler ve cerrahi teknik sayılabilir. ${ }^{[52,53]}$ Femoral komponentin dizilim bozukluğu, patello-femoral eklemdeki yük dağılımını değiştirerek kısmi çıkığa ve böylece patellar kırığa neden olabilir. ${ }^{[55]}$ Patella çevresindeki yumuşak dokunun aşırı sıyrılması, kanlanmayı bozarak osteonekroza ve kırığa yol açabilir. ${ }^{[52,54]}$ Patellanın asimetrik rezeksiyonu, patella üzerinde mekanik gerginliği arttırır. Az rezeksiyon ise patella-implant kalınlığını arttırarak patello-femoral reaksiyon gücünü ve ekstansör mekanizmanın germe gücünü yükseltir. ${ }^{[52,53]}$ Ameliyat sırasında patellanın kontrolsüz eversiyonu, kırıklara veya patellar tendon yırtıklarına yol açabilir. ${ }^{[27]}$ Bundan dolayı, patellanın eversiyonunun zor olduğu olgularda, önce distal femoral kesi yapılarak eversiyon kolaylaştırılabilir. ${ }^{[27]}$ Büyük merkezi çıkıntısı olan patellar implant tasarımları, küçük çevresel çıkıntısı olan tasarımlarla karşılaştırıldığında, ön patellar gerginliğe neden olarak kırık riskini arttırmaktadır. ${ }^{[56]}$ Patellar implant uygulandıktan sonra, ameliyat öncesi kalınlık sağlanmalı ve kesi simetrik olmalıdır. ${ }^{[52]}$ Osteonekrozdan korunmak için, patella çevresi yumuşak dokular mümkün olduğunca az sıyrılmalı ve lateral retinakuler gevşetme esnasında, superior genikuler artere dikkat edilmelidir. ${ }^{[33,54]}$ 


\section{Sınıflandırma}

Goldberg ve arkadaşları, patella kırıklarını, kırık anatomisine, ekstansör mekanizmanın bütünlüğüne ve komponentlerin stabilitesine göre 4 gruba ayırmışlardır. ${ }^{[52]}$ Tip 1, patellanın periferinde görülür. Kırık hattı, patellar implant ve ekstansör mekanizma ile ilişkili değildir. Tip 2 kırıkta, ekstansör mekenizma ya da implant-kemik yüzeyinde devamlılık kaybı mevcuttur. Tip 3, patellanın alt kısmında oluşan kırıkları kapsarve iki alt katagoriye ayrılmıştır: Tip 3A, patellar bağ yırtığı var; Tip 3B, patellar bağ yırtığı yok. Tip 4 kırıklar ise patellar kırıklarla birlikte, patello-femoral çıkıkları kapsar.

\section{Tedavi}

Patellar komponette gevşeme olmadığı veya ekstansör mekanizmanın sağlam olduğu durumlarda konservatif tedavi iyi bir alternatiftir. ${ }^{[57,58]}$ Alt ekstremiteyi ekstansiyonda sabitleyerek, kırık iyileşmesinin radyolojik bulguları görünene kadar hareketsiz bırakılarak tedavi edilebilir. ${ }^{\left[{ }^{[8]}\right.}$ Ortiguara ve arkadaşları, 37 hastada ayrışmamış periprostetik patella kırığını konservatif tedavi ederek, kaynama elde etmişlerdir. ${ }^{[54]}$

Ekstansör mekanizmanın bütünlüğünün bozulduğu durumlarda, patellar komponentin stabilitesine bakmadan cerrahi müdahale gerekir. Bu konuda yaygın kabul görmüş bir protokol yoktur ve komplikasyon oranı yaklaşık \%50 ile oldukça yüksektir. ${ }^{[5,6]}$ Bundan dolayı, ekstansör gevşeklik ve/veya kuadriseps zayıflığına yol açabilmesine rağmen, küçük kemik parçalarının eksizyonu ve kalan ekstansör mekanizmanın kemiğe tespiti ile rekonstrüksiyon yapılabilir. ${ }^{[59]}$

Patellar komponentin gevşemesi durumunda, gevşek implant çıkarılmalıdır. ${ }^{[54]}$ Kemik stoğu kalınlığı 10 mm'den fazlaolduğunda, tekrar implantasyon veya patellaplasti kabul edilebilir bir seçenektir. ${ }^{[31]}$ Ciddi kemik kaybı olduğunda ise, kısmen veya tamamen patellektomi uygulanabilir. ${ }^{[60]}$

\section{KAYNAKLAR}

1. Ritter MA, Thong AE, Keating EM, Faris PM, Meding JB, Berend ME, Pierson JL, Davis KE. The effect of femoral notching during total knee arthroplasty on the prevalence of postoperative femoral fractures and on clinical outcome. J Bone Joint Surg Am 2005;87(11):2411-4.

2. Aaron RK, Scott R. Supracondylar fracture of the femur after total knee arthroplasty. Clin Orthop Relat Res 1987;(219):136-9.

3. Inglis AE, Walker PS. Revision of failed knee replacements using fixed-axis hinges. J Bone Joint Surg Br 1991;73(5):757-61.

4. Lindahl $\mathrm{H}$. Epidemiology of periprosthetic femur fracture around a total hip arthroplasty. Injury 2007;38(6):651-4.

5. Berry DJ, RandJA. Isolated patellar component revision of total knee arthroplasty. Clin Orthop Relat Res 1993;(286):110-5.
6. Dorr LD. Fractures following total knee arthroplasty. Orthopedics 1997;20(9):848-50.

7. Felix NA, Stuart MJ, Hanssen AD. Periprosthetic fractures of the tibia associated with total knee arthroplasty. Clin Orthop Relat Res 1997;(345):113-24.

8. Smith WJ, Martin SL, Mabrey JD. Use of a supracondylar nail for treatment of a supracondylar fracture of the femur following total knee arthroplasty. J Arthroplasty 1996;11(2):210-3.

9. Tharani R, Nakasone C, Vince KG. Periprosthetic fractures after total knee arthroplasty. J Arthroplasty 2005;20(4 Suppl 2):27-32.

10. DiGioia AM 3rd, Rubash HE. Periprosthetic fractures of the femur after total knee arthroplasty. A literature review and treatment algorithm. Clin Orthop Relat Res 1991;(271):135-42.

11. Wood GC, Naudie DR, McAuley J, McCalden RW. Locking compression plates for the treatment of periprosthetic femoral fractures around well-fixed total hip and knee implants. J Arthroplasty 2011;26(6):886-92. CrossRef

12. Buttaro MA, Farfalli G, Paredes Núñez M, Comba $F$, Piccaluga F. Locking compression plate fixation of Vancouver type-B1 periprosthetic femoral fractures. J Bone Joint Surg Am 2007;89(9):1964-9.

13. Figgie MP, Goldberg VM, Figgie HE 3rd, Sobel M. The results of treatment of supracondylar fracture above total knee arthroplasty. J Arthroplasty 1990;5(3):267-76.

14. Neer CS 2nd, Grantham SA, Shelton ML. Supracondylar fracture of the adult femur. A study of one hundred and ten cases. J Bone Joint Surg Am 1967;49(4):591-613.

15. Chen F, Mont MA, Bachner RS. Management of ipsilateral supracondylar femur fractures following total knee arthroplasty. J Arthroplasty 1994;9(5):521-6.

16. Rorabeck $\mathrm{CH}$, Taylor JW. Periprosthetic fractures of the femur complicating total knee arthroplasty. Orthop Clin North Am 1999;30(2):265-77.

17. Su ET, DeWal H, Di Cesare PE. Periprosthetic femoral fractures above total knee replacements. J Am Acad Orthop Surg 2004;12(1):12-20.

18. Kim KI, Egol KA, Hozack WJ, Parvizi J. Periprosthetic fractures after total knee arthroplasties. Clin Orthop Relat Res 2006;446:167-75.

19. Hirsh DM, Bhalla S, Roffman M. Supracondylar fracture of the femur following total knee replacement. Report of four cases. J Bone Joint Surg Am 1981;63(1):162-3.

20. Figgie MP, Inglis AE, Mow CS, Wolfe SW, Sculco TP, Figgie $\mathrm{HE}$ 3rd. Results of reconstruction for failed total elbow arthroplasty. Clin Orthop Relat Res 1990;(253):123-32.

21. Li CH, Chen TH, Su YP, Shao PC, Lee KS, Chen WM. Periprosthetic femoral supracondylar fracture after total knee arthroplasty with navigation system. J Arthroplasty 2008;23(2):304-7. CrossRef

22. Engh GA, Ammeen DJ. Periprosthetic fractures adjacent to total knee implants: treatment and clinical results. Instr Course Lect 1998;47:437-48.

23. Culp RW, Schmidt RG, Hanks G, Mak A, Esterhai JL Jr, Heppenstall RB. Supracondylar fracture of the femur following prosthetic knee arthroplasty. Clin Orthop Relat Res 1987;(222):212-22.

24. Lesh ML, Schneider DJ, Deol G, Davis B, Jacobs CR, Pellegrini $V D \mathrm{Jr}$. The consequences of anterior femoral notching in total knee arthroplasty. A biomechanical study. J Bone Joint Surg Am 2000;82-A(8):1096-101. 
25. Zalzal P, Backstein D, Gross AE, Papini M. Notching of the anterior femoral cortex during total knee arthroplasty characteristics that increase local stresses. J Arthroplasty 2006;21(5):737-43.

26. Lewis PL, Rorabeck $\mathrm{CH}$. Periprosthetic fractures. In: Engh $\mathrm{GA}$, Rorabeck $\mathrm{CH}$, editors. Revision Total Knee Arthroplasty. Baltimore: Lippincott Williams \& Wilkins; 1997.

27. Backstein D, Safir O, Gross A. Periprosthetic fractures of the knee. J Arthroplasty 2007;22(4 Suppl 1):45-9.

28. Dennis DA. Periprosthetic fractures following total knee arthroplasty. Instr Course Lect 2001;50:379-89.

29. Maestro A, Rodríguez L, Llopis JA. Periprosthetic knee fractures. Rev Esp Cir Ortop Traumatol 2008;52:179-87.

30. Merkel KD, Johnson EW Jr. Supracondylar fracture of the femur after total knee arthroplasty. J Bone Joint Surg Am 1986;68(1):29-43.

31. Althausen PL, Lee MA, Finkemeier CG, Meehan JP, Rodrigo JJ. Operative stabilization of supracondylar femur fractures above total knee arthroplasty: a comparison of four treatment methods. J Arthroplasty 2003;18(7):834-9.

32. Farouk $O$, Krettek C, Miclau T, Schandelmaier P, Guy $P$, Tscherne $\mathrm{H}$. Minimally invasive plate osteosynthesis: does percutaneous plating disrupt femoral blood supply less than traditional technique? J Orthop Trauma 1999;13(6):401-6.

33. Herrera DA, Kregor PJ, Cole PA, Levy BA, Jönsson A, Zlowodzki $M$. Treatment of acute distal femur fractures above a total knee arthroplasty: systematic review of 415 cases (19812006). Acta Orthop 2008;79(1):22-7. CrossRef

34. Erhardt JB, Grob K, Roderer G, Hoffmann A, Forster TN, Kuster MS. Treatment of periprosthetic femur fractures with the non-contact bridging plate: a new angular stable implant. Arch Orthop Trauma Surg 2008;128(4):409-16.

35. Egol KA, Kubiak EN, Fulkerson E, Kummer FJ, Koval KJ. Biomechanics of locked plates and screws. J Orthop Trauma 2004;18(8):488-93.

36. Bottlang M, Doornink J, Fitzpatrick DC, Madey SM. Far cortical locking can reduce stiffness of locked plating constructs while retaining construct strength. J Bone Joint Surg Am 2009;91(8):1985-94. CrossRef

37. Haidukewych GJ, Jacofsky DJ, Hanssen AD. Treatment of periprosthetic fractures around a total knee arthroplasty. J Knee Surg 2003;16(2):111-7.

38. Johnston AT, Tsiridis E, Eyres KS, Toms AD. Periprosthetic fractures in the distal femur following total knee replacement: A review and guide to management. Knee 2012;19(3):15662. CrossRef

39. Ebraheim NA, Sochacki KR, Liu X, Hirschfeld AG, Liu J. Locking plate fixation of periprosthetic femur fractures with and without cerclage wires. Orthop Surg 2013;5(3):183-7. CrossRef

40. Gliatis J. Periprosthetic distal femur fracture: plate versus nail fixation. Opinion: intramedullary nail. J Orthop Trauma 2007;21(3):220-1.

41. Chen SH, Yu TC, Chang CH, Lu YC. Biomechanical analysis of retrograde intramedullary nail fixation in distal femoral fractures. Knee 2008;15(5):384-9. CrossRef
42. Bobak P, Polyzois I, Graham S, Gamie Z, Tsiridis E. Nailed cementoplasty: a salvage technique for Rorabeck type II periprosthetic fractures in octogenarians. J Arthroplasty 2010;25(6):939-44. CrossRef

43. Ruchholtz S, Tomás J, Gebhard F, Larsen MS. Periprosthetic fractures around the knee -the best way of treatment. Eur Orthop Traumatol 2013;4(2):93-102.

44. Maniar RN, Umlas ME, Rodriguez JA, Ranawat CS. Supracondylar femoral fracture above a PFC posterior cruciate-substituting total knee arthroplasty treated with supracondylar nailing. A unique technical problem. J Arthroplasty 1996;11(5):637-9.

45. Lee SS, Lim SJ, Moon XW, Seo JG. Outcomes of long retrograde intramedullary nailing for periprosthetic supracondylar femoral fractures following total knee arthroplasty. Arch Orthop Trauma Surg 2014;134(1):47-52. CrossRef

46. Ristevski B, Nauth A, Williams DS, Hall JA, Whelan DB, Bhandari M, Schemitsch EH. Systematic review of the treatment of periprosthetic distal femur fractures. J Orthop Trauma 2014;28(5):307-12. CrossRef

47. Cantu RV, Koval KJ. The use of locking plates in fracture care. J Am Acad Orthop Surg 2006;14(3):183-90.

48. Marya SKS, Kacker S, Singh C, Periprosthetic fractures -a review article. J Clin Orthop Trauma 2011;2(1):3-11. CrossRef

49. Lotke PA, Ecker ML. Influence of positioning of prosthesis in total knee replacement. J Bone Joint Surg Am 1977;59(1):77-9.

50. Hanssen AD, Stuart MJ. Treatment of periprosthetic tibial fractures. Clin Orthop Relat Res 2000;(380):91-8.

51. Yoo JD, Kimm NK. Periprosthetic fractures following total knee arthroplasty. Knee Surg Relat Res 2015;27(1):1-9. CrossRef

52. Goldberg VM, Figgie HE 3rd, Inglis AE, Figgie MP, Sobel M, Kelly M, Kraay M. Patellar fracture type and prognosis in condylar total knee arthroplasty. Clin Orthop Relat Res 1988;(236):115-22.

53. Windsor RE, Scuderi GR, Insall JN. Patellar fractures in total knee arthroplasty. J Arthroplasty 1989;4 Suppl: S63-7.

54. Ortiguera CJ, Berry DJ. Patellar fracture after total knee arthroplasty. J Bone Joint Surg Am 2002;84-A(4):532-40.

55. Huberti $\mathrm{HH}$, Hayes WC. Patellofemoral contact pressures. The influence of $q$-angle and tendofemoral contact. J Bone Joint Surg Am 1984;66(5):715-24.

56. Goldstein SA, Coale E, Weiss AP, Grossnickle M, Meller B, Matthews LS. Patellar surface strain. J Orthop Res 1986;4(3):372-7.

57. Le AX, Cameron HU, Otsuka NY, Harrington IJ, Bhargava $M$. Fracture of the patella following total knee arthroplasty. Orthopedics 1999;22(4):395-8.

58. Parvizi J, Kim KI, Oliashirazi A, Ong A, Sharkey PF. Periprosthetic patellar fractures. Clin Orthop Relat Res 2006;446:161-6.

59. Keating EM, Haas G, Meding JB. Patella fracture after post total knee replacements. Clin Orthop Relat Res 2003;(416):93-7.

60. Chalidis BE, Tsiridis E, Tragas AA, Stavrou Z, Giannoudis PV. Management of periprosthetic patellar fractures. A systematic review of literature. Injury 2007;38(6):714-24. 